\title{
Study on the preparation of multi element liquid fertilizer using restaurant garbage slurry as raw material by MBR membrane technology*
}

\author{
Yi-Fan Chen ${ }^{1,2, a}$, Gong-Bin Tang ${ }^{1,2}$, Feng Xiao ${ }^{1,2}$, Shan-Shan Zhang ${ }^{1,2}$, \\ $\mathrm{Yu}-\mathrm{Yuan} \mathrm{Lu}^{3}$ and Fu-Chuan Huang ${ }^{1,2, \mathrm{~b} \dagger}$ \\ ${ }^{1}$ School of Chemistry and Chemical Engineering, Guangxi University, \\ Nanning, 530004, China \\ ${ }^{2}$ Key Laboratory of Guangxi Petrochemical Resource Processing and Process \\ Intensification Technology \\ Nanning, 530004, China \\ ${ }^{3}$ Guangxi Yulin Dazhi Biotechnology Investment Company Limited, \\ Yulin, 537000, China \\ ${ }^{a}$ E-mail: 739430809@qq.com; ${ }^{\dagger}, b$ E-mail: huangfuchuan@gxu.edu.cn
}

\begin{abstract}
There is a problem with a larger number of biogas slurry continuous emissions in the biogas slurry poor, and emissions is beyond of one time given the regularity of crop fertilization. This research introduces a production engineering that using the restaurant garbage as raw materials of biogas slurry, using MBR membrane technology for effective nutrient enrichment, by using biochemical technology to the product efficient of special multi element liquid fertilizer. Finally make the restaurant garbage harmless, reduction, recycling and maximize economic benefits come true.
\end{abstract}

Keywords: Restaurant Garbage; Biogas Slurry; MBR; Multi Elements Liquid Fertilizer.

\section{Introduction}

The special multi element liquid fertilizer that has been used widely in ecological agriculture, trickle irrigation and sprinkler irrigation in modern the liquid fertilizer. It has excellent application effect and convenience. Due to the characteristics of restaurant garbage, making the restaurant garbage as raw materials by fermentation to produce renewable energy sources such as methane and hydrogen etc, which is a common and very effective method restaurant garbage recycling[1].Use restaurant garbage fermentation to produce biogas slurry to create special multi element liquid fertilize by MBR membrane technology. It is a very effective method to achieve for optimization of environment protection and the maximization of economic benefit.

\footnotetext{
* This research was supported financially by the China Spark Program (2015GA790003).
} 


\section{The Development of Eat Hutch Waste Treatment Technology}

The core restaurant garbage disposal is achieve the effect of environmental protection and uses solid waste, which through the biological treatment technology. At present the commonly method about the restaurant garbage disposal is uses the restaurant garbage fermentation to produce methane, hydrogen and organic compost. As shown in Table 1[5], restaurant garbage as raw material of fermentation to produce biogas slurry is rich in nitrogen, phosphorus and potassium. In terms of food waste as the raw materials for liquid fertilizer, it will get a very good base liquid fertilizer.

Table 1. Restaurant garbage as raw material slurry with nitrogen, phosphorus and potassium content

\begin{tabular}{ll}
\hline Element & $\begin{array}{l}\text { Restaurant garbage as raw material of fermentation to } \\
\text { produce biogas slurry content of nitrogen, phosphorus and } \\
\text { potassium. \% }\end{array}$ \\
\hline Total nitrogen mass fraction & 0.124 \\
Total phosphorus mass fraction & 0.0063 \\
Total potassium mass fraction & 0.026 \\
\hline
\end{tabular}

\section{Special Multi Element Liquid Fertilizer and Liquid Fertilizer Production Process Development:}

The special multi element liquid fertilizer originated from multi element liquid fertilizer or integrative water and fertilizer in technology. Usually liquid fertilizer can be divided into two types: the suspending liquid fertilizer and supernatant liquid fertilizer. These two kinds of liquid fertilizer in use process have its own characteristics. Compared with the traditional solid fertilizer, the multi element liquid fertilizer has obvious advantages of characteristics. The fertilizer efficiency of multi element liquid fertilizer more than traditional solid compound fertilizer to $30 \%$. [2, 3].

\section{Special Multi Element Liquid Fertilizer Manufacturing Process}

\subsection{Traditional craft to make multi element fertilizer:}

In terms of the manufacturing base liquid fertilizer, the main application includes ammonia solution and ammonium polyphosphate solution. The main methods of ammonia solution are discontinuous process and the continuous process two methods. The discontinuous process is shown in Figure 1[4]. The continuous process is shown in Figure 2[4].

In the production process of clear liquid base fertilizer ammonium polyphosphate (APP) solution, the commonly used methods include Phosphoric Acid Production by hot process, poly phosphoric acid production and the 
method of urea phosphate production the basic process principle diagram as shown in Figure 3[4].

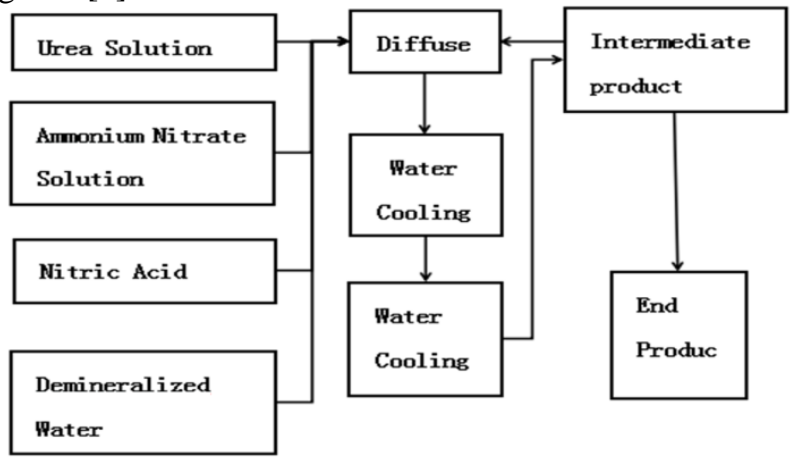

Fig. 1. The discontinuous process.

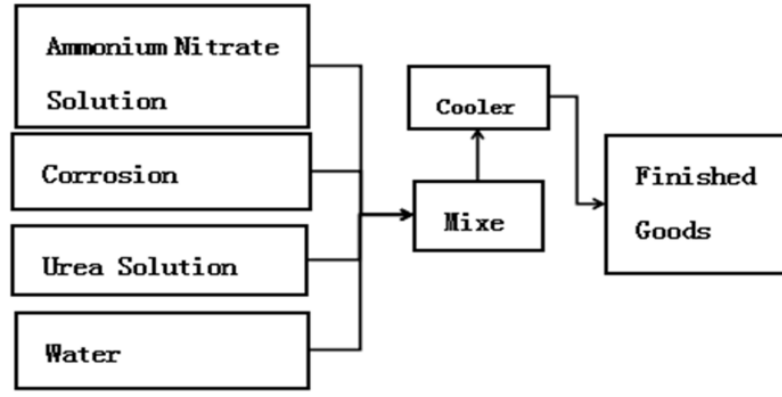

Fig. 2. The continuous process.

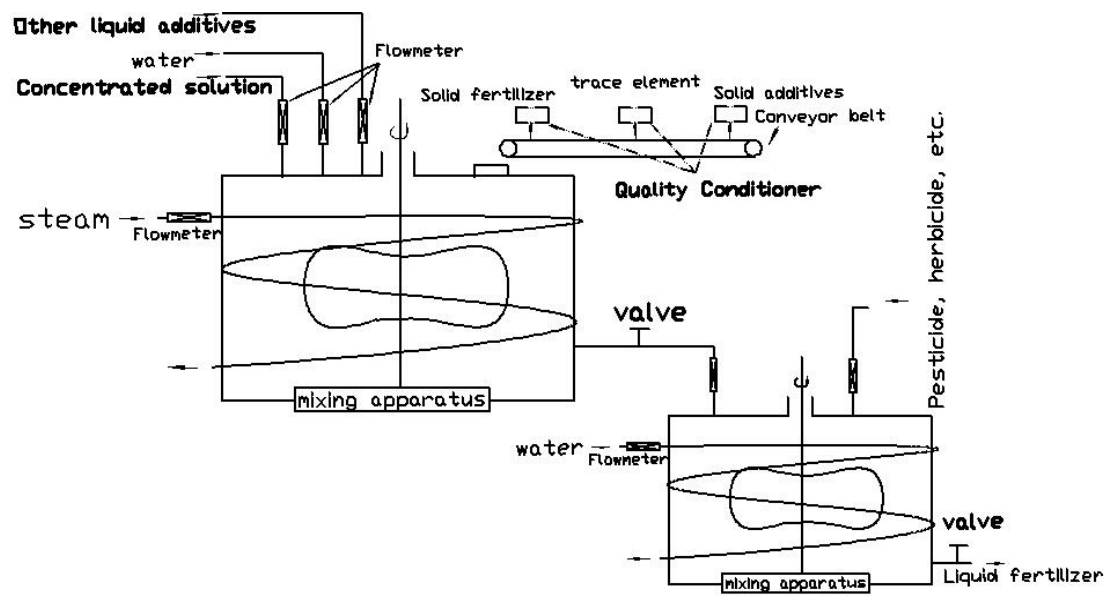

Fig. 3. The basic process principle diagram. 


\subsection{Process of using MBR membrane technology enrichment the biogas slurry to producing multi element liquid fertilizer}

The biogas slurry is rich in a variety of plant growth necessary nutrient elements, which is restaurant garbage anaerobic fermentation to produce, If the removal of chlorine ion of biogas slurry, enrichment the biogas slurry, according to the needs of different plants in different growth period, to join a certain amount related nutrient elements of the plant need, to manufacturing compound special multi element liquid fertilizer.

\subsubsection{Process composition and principle}

The production process mainly includes MBR membrane reactor, tubular reactor, heat exchanger, process control system, heating system and metering device, etc. Among them the tubular reactor system is mainly composed of mixing tank, circulating pump, agitator, heat exchanger flow controllers, and quality controller and so on.

The main system principle is, put into the MBR membrane reactor to cross flow enrichment after biogas slurry filtration. Structure principle as shown in Figure 4. The biogas slurry after the MBR membrane enrichment and deodorization that called concentrated solution or base liquid. In accordance with the requirements for specific fertilizer formulations, it need to join some prefabricated zinc, manganese, boron rock mixtures, compounds containing nitrogen, phosphorus ,potassium, trace elements, pesticide, herbicide, etc. Finally, it through the mixed reaction processing to acquire multi element liquid fertilizer. To note: Advantage of the characteristics of the MBR membrane technology in the treatment process of the biogas slurry, biogas slurry can be controlled by control time and strains in MBR membrane reactor, to enhance the decomposition rates of stench gas such as $\mathrm{H}_{2} \mathrm{~S}$, methyl mercaptan, VOCs .

\subsubsection{Production process design}

Using the MBR membrane technology to manufacturing the multi element liquid by using the restaurant garbage as raw materials of biogas slurry. As shown in Figure 4. The biogas slurry that raw materials restaurant garbage, through the filtered into the MBR membrane reactor. Enrichment through the reactor to obtain a desired concentration of the base fluid. Process principle as shown in Figure 5. In the production process, in turn, through microfiltration, ultra-filtration, nanofiltration, reverse osmosis to intercept. Set a bracket between in membrane, and open the drain valve regularly to control the concentration between the membranes. Drain valve to discharge the liquid containing certain plant nutrition elements, can be directly to concentrate. By 
controlling the parameters such as pressure, temperature and flow rate to control the enrichment concentration and the cleanliness of the reclaimed water. Through reflux device, and reclaimed water backflow on a regular basis to reduce the membrane fouling of MBR membrane reactor. Will get the base liquid fertilizer into the mix reaction equipment. According to the needed nutrients of the liquid fertilizer, deployment zinc, manganese, boron rock and prefabricated suspending agent mixing, and in accordance with the proportion to join trace element and other additives. After the mixed reaction process, the base liquid fertilizer by adding nitrogen, phosphorus and potassium compounds, in order to improve the nitrogen, phosphorus, potassium concentration in the base liquid fertilizer and control the $\mathrm{pH}$ value. Finally add the relevant herbicides, pesticides, etc. To obtain the finished product multi element special liquid fertilizer.

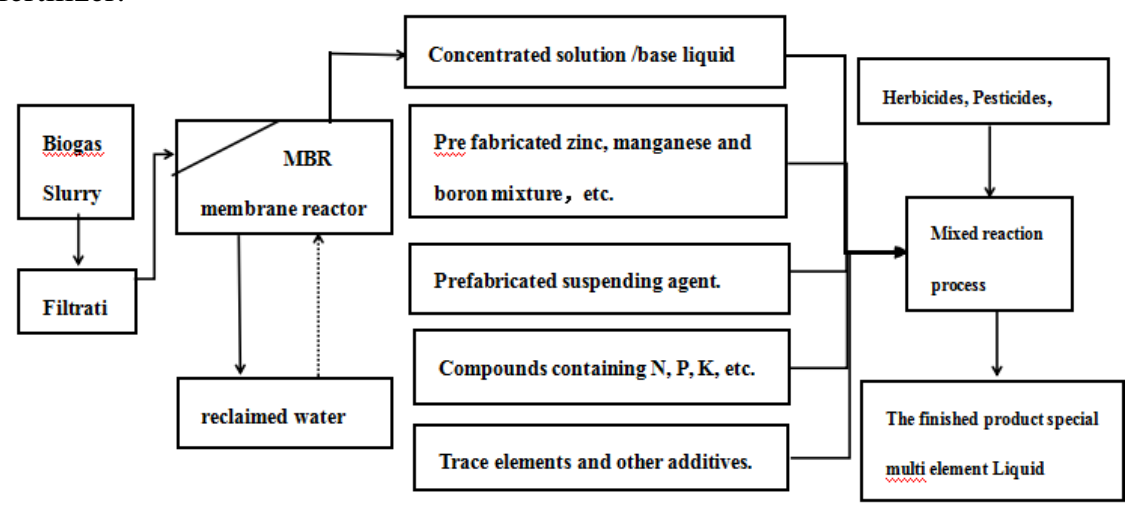

Fig. 4. Process design.

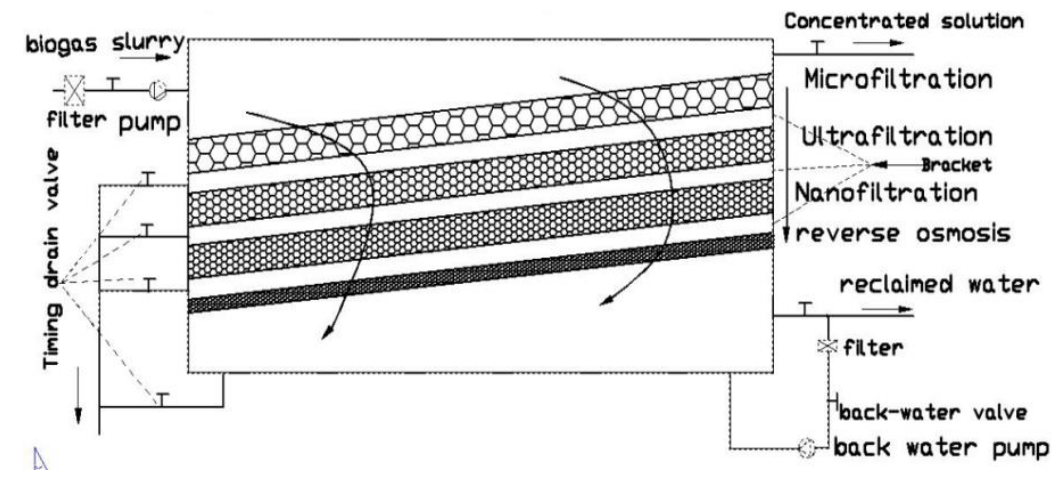

Fig. 5. MBR membrane reactor.

Special purpose blueberries fertilizer:

Blueberries are appropriate for the soil loose and humid, good circulation of 
air, high organic matter content of acidic silty loam, sandy soil to grow. For to keep the growth of blueberries and yield rich, the suitable fertilization and irrigation methods is drip irrigation, sprinkler irrigation and infiltration irrigation. Blueberry is suitable for the growth of 4.0 5.5 in the $\mathrm{pH}$ of the soil. High PH could cause the blueberry iron deficiency chloros is, plants are in a state of sub health and the decline in output [6].

The principal preparation methods of special purpose blueberry fertilizer is: (1)Taking borax, ferrous sulfate, ferric sulfate, zinc sulfate, manganese sulfate, magnesium carbonate mix according to 20:30:30:10:1:20 proportion. (2) fter mixing phosphate, potassium sulfate, ammonium sulfate to $1: 3: 20$, constant temperature dissolution and mixed with base fluid in tubular reactor. The restaurant garbage as raw materials of biogas slurry into MBR membrane reactor made the base fluid. (3)The mixture of the first step and the second parts to put into the reactor, obtain semi-finished liquid fertilizer. (4)Adding herbicides, pesticides and other pesticides to the semi product liquid fertilizer, then add the sweet-sour liquid to adjust PH value to $4.0 \sim 4.0$.

\section{Conclusion}

1. Using MBR membrane technology to the restaurant garbage as raw materials of biogas slurry to produce multi element liquid fertilizer process. Implementation restaurant garbage efficient resource utilization. This process could not only solved the problem of a large number of biogas slurry discharge, but also implements the eat hutch garbage disposal to achieve the effect of no waste discharge.

2. The technology to produce multi-element liquid fertilizer is feasible by MBR membrane using the food waste as raw materials of biogas slurry.

3. The manufacture of liquid fertilizer technology, which is beneficial to achieve the water, fertilizer and pesticide the application of integration technology in the liquid fertilizer, but also is beneficial to the promotion of modern organic ecological agriculture technology application.

\section{References}

1. Du Xin and Chen Ting (eds.).Environmental impact analysis of two typical restaurant garbage regeneration technologies [J].Chinese Journal of Environmental Engineering, 2010, 4(1): 189-194. In Chinese

2. ZHAO Yun-li. Integrative water-fertilizer technology and liquid fertilizer [J]. Nitrogenous Fertilizer Technology, 2013, 34(5): 46-48. In Chinese

3. Jiang bai-wen. Fertilizer processing technology and equipment [Z].Beijing: Chemical Industry Press, 2013. In Chinese

4. Xie tian biao, Li yu chun. Liquid fertilizer [M].Beijing: 1990. In Chinese 
5. Li Yi-wen and QU Ying-hua, (Eds.). Change of Nutrition Contents of Biogas Slurry with Different Fermentation Raw Materials [J]. China Biogas, 2012, 30(3): 17-20. In Chinese

6. Den jian. Effects of different fertilizers on the growth and fruit of Blueberry [J]. Northern Fruits, 2015, 7(4): 12-13. In Chinese 